\title{
Nutrient deficiencies as a risk factor in Taiwanese patients with postherpetic neuralgia
}

\author{
Jen-Yin Chen ${ }^{1,2,3}$, Chin-Chen Chu ${ }^{1}$, Yung-Song Lin $^{4}$, Edmund Cheng So ${ }^{1}$, Ja-Ping Shieh ${ }^{1}$ and \\ Miao-Lin $\mathrm{Hu}^{2,5 *}$ \\ ${ }^{1}$ Department of Anesthesiology, Chi Mei Medical Center, Tainan, Taiwan, ROC \\ ${ }^{2}$ Department of Food Science and Applied Biotechnology, National Chung Hsing University, Taichung, Taiwan, ROC \\ ${ }^{3}$ Department of the Senior Service Management, Chia Nan University of Pharmacy and Science, Tainan, Taiwan, ROC \\ ${ }^{4}$ Department of Otolaryngology, Chi Mei Medical Center, Taipei Medical University, Tainan, Taiwan, ROC \\ ${ }^{5}$ Institute of Nutrition, China Medical University, Taichung, Taiwan, ROC
}

(Received 27 July 2010 - Revised 31 October 2010 - Accepted 20 January 2011 - First published online 8 April 2011)

\section{Abstract}

Postherpetic neuralgia (PHN) is the most common complication of herpes zoster (HZ). The aim of the present study was to compare the nutritional status of PHN patients with that of healthy controls, and then to identify risk factors for PHN using multivariate multiple logistic regressions. In the present cross-sectional study, we prospectively enrolled fifty PHN patients for at least 3 months and fifty healthy controls. We selected nine circulating nutrients including ionised $\mathrm{Ca}, \mathrm{Zn}$, retinol, folic acid, vitamin $\mathrm{B}_{12}$, vitamin $\mathrm{C}, \alpha$-tocopherol, $\gamma$-tocopherol and lycopene associated with both immunity and the modulation of neuropathic pain, and measured their concentrations in plasma/serum. Concentrations of ionised $\mathrm{Ca}, \mathrm{Zn}$, vitamin $\mathrm{C}$ and vitamin $\mathrm{B}_{12}$ were significantly lower in PHN patients than in controls after excluding those patients receiving supplements since the outbreak of HZ. The prevalence of either mild/marginal or severe deficiencies for any of the nine selected circulating nutrients in PHN patients $(92 \%)$ was much higher than that in controls (46\%) $(P<0 \cdot 001)$. Lower concentrations of vitamin $\mathrm{C}(\leq 45.0 \mu \mathrm{mol} / \mathrm{l})$, ionised $\mathrm{Ca}(\leq 1.05 \mathrm{mmol} / \mathrm{l})$ and $\mathrm{Zn}(\leq 0.91 \mathrm{~g} / \mathrm{l})$ were found to increase independently the risk of PHN using binary variable (dichotomy) analyses with both PHN patients and controls in a multivariate logistic regression analysis. No significant correlations existed between the risks of PHN and the concentrations of retinol, folic acid, vitamin $\mathrm{B}_{12}$, lycopene or $\alpha$ : $\gamma$-tocopherol ratios. Thus, lower concentrations of circulating nutrients, namely vitamin $\mathrm{C}$, ionised $\mathrm{Ca}$ or Zn, are probably a risk factor in Taiwanese patients with PHN.

Key words: Nutritional status: Herpes zoster: Postherpetic neuralgia: Nutrient deficiencies: Risk factors

Postherpetic neuralgia (PHN), a peripheral neuropathic pain syndrome, is the most common complication of herpes zoster $(\mathrm{HZ})^{(1)}$. PHN can lead to long-term psychological distress, physical disability and tremendous use of health care resources ${ }^{(2)}$. Therefore, to identify risk factors for PHN and to effectively improve preventive strategies are clinically meaningful. Although old age, female sex, presence of a prodrome, greater acute pain severity, presence of severe $\operatorname{rash}^{(3)}$ and immunocompromised patients ${ }^{(1)}$ have been identified as independent predictors of PHN, discovering additional risk factors is still needed to prevent developing PHN with respect to $\mathrm{HZ}$ management ${ }^{(3)}$.

An outbreak of $\mathrm{HZ}$ caused by a reactivation of latent varicella zoster virus (VZV) is primarily attributed to a reduction in host cellular immunity ${ }^{(1)}$. Additionally, two non-mutually exclusive theories of PHN are an alteration in the excitability of central neurons and a chronic active VZV ganglionitis caused by ongoing viral activity in patients developing PHN compared with HZ patients who do not ${ }^{(1,4)}$. Thus, reduced cellular immunity plays a critical factor in both zoster risk and the persistence of $\mathrm{PHN}^{(1,4)}$. Diminished cellular immunity has been advocated to be closely associated with deficiencies of nutrients ${ }^{(5,6)}$. A case-control study using a FFQ illustrates a strong dose-response relationship between decreasing vitamin $\mathrm{C}$ intake and increasing zoster risk $^{(7)}$. Our previous study has demonstrated that PHN patients have lower plasma concentrations of vitamin $\mathrm{C}$ than healthy controls, and that short-term intravenous administration of megadose vitamin $\mathrm{C}$ partially reduces their spontaneous pain effectively but not allodynia in PHN patients ${ }^{(8)}$. However, a single nutrient is thought to have relatively weak effects on the zoster risk $^{(7)}$. It is possible that deficiencies in other nutrients, in

Abbreviations: HZ, herpes zoster; PHN, postherpetic neuralgia; VZV, varicella zoster virus. 
addition to vitamin $\mathrm{C}$, may also contribute to the zoster risk and PHN. Nutrients including vitamins $A, C, E$ and $B_{12}$ and $\mathrm{Zn}$ have been shown to manifest a direct antiviral effect $^{(9-11)}$, while folic acid ${ }^{(6)}$, lycopene ${ }^{(12)}$ and $\mathrm{Ca}^{(13)}$ have been reported to support immune responses. All these nutrients are also involved in the modulation of neuropathic pain. For instance, prophylactic vitamin $\mathrm{C}$ has been recommended in two randomised controlled trials and in an evidence-based guideline for the prevention of complex regional pain syndrome type I, a form of peripheral neuropathic pain syndrome ${ }^{(14-16)}$. Hypocalcaemia has been shown to decrease the pain threshold to enhance pain transmission in rats $^{(17)}$. Folic acid deficiency has been demonstrated in subsequent peripheral neuropathy in human subjects $^{(18)}$. Nutrient supplements, including vitamin $\mathrm{A}^{(19)}$, vitamin $\mathrm{B}_{12}^{(20)}$, vitamin $\mathrm{E}^{(21)}$, lycopene ${ }^{(22)}$ and $\mathrm{Zn}^{(23)}$, have been reported to ameliorate neuropathic pain in rats. Furthermore, ascorbate ${ }^{(24)}$ and $\mathrm{Zn}^{(25)}$ are $\mathrm{Ca}(\mathrm{v}) 3.2 \mathrm{~T}$-channel blockers that have been shown to modulate neuronal excitability and to alleviate neuropathic pain in rats.

To the best of our knowledge, no published studies have examined the plasma/serum status of nutrients in PHN patients. The aim of the present study was to compare plasma/serum concentrations of selected nutrients in PHN patients with those of healthy controls. We selected nine circulating nutrients including ionised $\mathrm{Ca}, \mathrm{Zn}$, retinol, folic acid, vitamin $\mathrm{B}_{12}$, vitamin $\mathrm{C}, \boldsymbol{\alpha}$-tocopherol, $\boldsymbol{\gamma}$-tocopherol and lycopene associated with both immunity and the modulation of neuropathic pain, and measured their concentrations in plasma/serum. In addition, we used multivariate multiple logistic regression analyses to analyse the relationship between plasma nutrients and the risk of PHN.

\section{Experimental methods}

\section{Study site, subjects and study groups}

The present study was conducted according to the guidelines laid down in the Declaration of Helsinki, and all procedures involving human subjects or patients were approved by the Institutional Ethics Committee of Chi Mei Medical Center, Tainan, Taiwan. Informed consent was obtained from all PHN patients and control volunteers. All subjects had the opportunity to withdraw from the study at any time. To examine the plasma status of nine selected nutrients, we recruited Taiwanese PHN patients visiting the Pain Clinic of Chi Mei Medical Center and healthy volunteers from 2004 to 2005. PHN is defined as the presence of a worst pain score of $\geq 3$ on an eleven-point numeric rating pain scale at 3 months or longer after zoster rash onset ${ }^{(2)}$. For each patient, a questionnaire was administered recording age, sex, body height, body weight, medical history, occurrence of poor appetite, irregular meal pattern, occurrence of insomnia, psychological distress, physical disabilities, intensity of average daily pain in the previous $24 \mathrm{~h}$ and duration of pain from cutaneous vesicular rash onset to the first visit or referral to our Pain Clinic. The intensity of average daily pain was graded on an eleven-point numeric rating pain scale from 0 to 10 (with 0 being no pain at all and 10 being the worst pain imaginable $)^{(2)}$. Patients with ratings on the pain scale $\geq 3$ were included $^{(2)}$. Control subjects were healthy Taiwanese volunteers from a hospitalbased pool. Those who regularly took vitamins/mineral supplements and who had chronic pain (numeric rating pain scale $\geq 3)$ as well as those who had an infection or an admission history in the previous 6 months were excluded from the control subjects of the present study.

\section{Specimen collection, handling and biochemical determination}

After an overnight fast, blood samples drawn from the patients and control subjects into (1) ethylenediaminetetra-acetic acid vacutainers, (2) Li heparin vacutainers and (3) vacutainers containing clot activator and serum separator gel were transported to the laboratory in a light-excluding container and stored for not more than $6 \mathrm{~h}$ at $4^{\circ} \mathrm{C}$ before centrifugation. After centrifugation at $3000 \mathrm{~g}$ at $4^{\circ} \mathrm{C}$ for $10 \mathrm{~min}$, separated plasma was stored frozen at $-80^{\circ} \mathrm{C}$. Plasma concentrations of lipophilic antioxidants including retinol, $\alpha$-tocopherol, $\gamma$-tocopherol and lycopene were determined, as described previously $^{(26)}$. Plasma vitamin $\mathrm{C}$ concentration was determined using the automated enzymatic $\operatorname{method}^{(8)}$. Ionised Ca was determined in whole blood by ion-selective electrode using a Bayer Corning 855 (Bayer Co., Pittsburgh, PA, USA). Serum folic acid and vitamin $\mathrm{B}_{12}$ concentrations were determined by chemiluminescence using a Siemens Centaur (Bayer Co., Pittsburgh, PA, USA). Serum Zn concentration was determined by flame atomic absorption using a PerkinElmer AAnalyst 800 (PerkinElmer Co., Waltham, MA, USA). For each element, a calibration curve was performed using commercial standards.

\section{Statistical analysis}

Data processing and statistical analysis were performed using SPSS for Windows, version 10.0.7 (SPSS, Inc., Chicago, IL, USA). Significance was accepted at the 5\% level. Owing to small sample sizes and lack of fit to a normal distribution for most measurements in the present study, data are expressed as means, standard deviations and medians, and were analysed using non-parametric statistics. The Mann-Whitney $U$ test was used to test the differences in age, body height, body weight and plasma/serum concentrations of nine nutrients including ionised $\mathrm{Ca}, \mathrm{Zn}$, retinol, folic acid, vitamin $\mathrm{B}_{12}$, vitamin $\mathrm{C}, \boldsymbol{\alpha}$-tocopherol, $\gamma$-tocopherol and lycopene between controls and PHN patients. The $\chi^{2}$ test was used to test the difference in sex between controls and PHN patients. The difference in the number of controls and PHN patients taking supplements irregularly was determined using Fisher's exact test. The difference in the prevalence of nutrient deficiency and the overall significance level of nutrient deficiencies between controls and PHN patients was also determined using Fisher's exact test. The difference in the number of nutrient deficiencies between controls and PHN patients was determined by the Mann-Whitney $U$ test.

$\mathrm{OR}$ as estimates of the relative risk of $\mathrm{PHN}$ in relation to plasma concentrations of seven nutrients including retinol, 
vitamin $\mathrm{C}$, vitamin $\mathrm{B}_{12}$, folic acid, lycopene, $\mathrm{Zn}$ and ionised $\mathrm{Ca}$, and the $\alpha: \gamma$-tocopherol ratio were calculated using multivariate multiple logistic regression models. Plasma concentrations of the seven nutrients and the $\alpha: \gamma$-tocopherol ratio were dichotomised into binary variables by the median of both controls and PHN patients. To identify the seven nutrients and the $\alpha: \gamma$-tocopherol ratio independently predicted to PHN, a multivariate multiple logistic regression model was constructed by forward stepwise procedures and used to estimate adjusted OR and their $95 \%$ CI. We assessed the discrimination using the $C$-statistic, which is a measure of the area under the curve of the receiver-operating characteristic curve. An area under the curve-receiver-operating characteristic value greater than 0.80 indicates a good discrimination.

\section{Results}

A total of fifty Taiwanese healthy controls (twenty-nine men and twenty-one women) and fifty Taiwanese patients (thirty men and twenty women) with PHN were included. Baseline characteristics of the healthy controls and PHN patients are shown in Table 1. There were no significant differences in sex, age, body heights or body weights between healthy controls and PHN patients.

\section{Plasma nutrient concentrations in healthy controls and postherpetic neuralgia patients}

In the present study, we recruited healthy control subjects who either did not take or did not regularly take vitamins/mineral supplements. Of the fifty healthy control subjects, seven (14\%) occasionally took one capsule of a supplement; among these subjects, four took multivitamins containing minerals, one took $\mathrm{Ca}$ and two took vitamin E. Of the fifty PHN patients, four ( $8 \%$ ) took one supplement (multivitamins and minerals) irregularly before outbreaks of $\mathrm{HZ}$. There was no statistical difference in numbers between controls and PHN patients taking supplements irregularly $(P=0 \cdot 16)$.
Table 2 shows that plasma/serum concentrations of ionised $\mathrm{Ca}, \mathrm{Zn}$, vitamin $\mathrm{C}$ and $\boldsymbol{\gamma}$-tocopherol were significantly lower in PHN patients than in controls. In contrast, $\alpha$-tocopherol and vitamin $\mathrm{B}_{12}$ were significantly higher in $\mathrm{PHN}$ patients than in controls. According to their past medical history, $56 \%$ of our patients had been prescribed intravenous or intramuscular vitamin $\mathrm{B}_{12}$, and $46 \%$ of them took oral $\alpha$-tocopherol supplements since outbreaks of HZ. Hence, we excluded those patients receiving either vitamin $\mathrm{B}_{12}$ or $\alpha$-tocopherol supplements since outbreaks of HZ. As a result, plasma concentrations of $\alpha$-tocopherol and $\gamma$-tocopherol in $\mathrm{PHN}$ patients were not significantly different from those in controls, whereas plasma concentrations of vitamin $\mathrm{B}_{12}$ in $\mathrm{PHN}$ patients were significantly lower than those in controls.

The mean concentration of plasma vitamin $\mathrm{C}$ in our controls was $76 \cdot 2$ (SD 31.2) $\mu \mathrm{mol} / 1$, which approaches the high level of the normal range $(26 \cdot 1-84 \cdot 6 \mu \mathrm{mol} / \mathrm{l})^{(27)}$, whereas the mean concentration of ionised $\mathrm{Ca}$ in whole blood in our controls was $1.10(\mathrm{SD} 0.08) \mathrm{mmol} / \mathrm{l}$ lower than the normal range $(1 \cdot 14-1 \cdot 30 \mathrm{mmol} / 1)^{(28)}$. Mean concentrations of serum $\mathrm{Zn}$ and vitamin $\mathrm{B}_{12}$ in our controls were within the normal ranges ${ }^{(29)}$ and were similar to mean concentrations of healthy elderly Taiwanese ${ }^{(30,31)}$.

Although the levels of plasma lycopene were not significantly different between controls and PHN patients, the levels in both groups were lower than the normal range ${ }^{(32)}$. The high prevalence of low lycopene concentrations in both controls and PHN patients was consistent with a previous report that plasma lycopene concentrations in Taiwanese elderly are lower than those in Western society (Table 4), probably because tomatoes consumed by Taiwanese elderly are usually not processed ${ }^{(33)}$

\section{Profiles of tocopherols and $\alpha$ : $\gamma$-tocopherol ratios}

As shown in Table 3, geometric mean concentrations of $\alpha$-tocopherol in controls were approximately $10 \cdot 8$-fold, compared with those of $\gamma$-tocopherol. $\alpha$ : $\gamma$-Tocopherol ratios in the twenty-seven PHN patients without $\alpha$-tocopherol

Table 1. Baseline characteristics of healthy controls and patients with postherpetic neuralgia (PHN)* (Mean values, standard deviations, medians and number of patients)

\begin{tabular}{|c|c|c|c|c|c|c|c|}
\hline & \multicolumn{3}{|c|}{ Healthy controls ( $n 50)$} & \multicolumn{3}{|c|}{ PHN patients $(n 50)$} & \multirow[b]{2}{*}{$P$} \\
\hline & Mean & SD & Median & Mean & SD & Median & \\
\hline $\operatorname{Sex}(n)$ & & & & & & & 0.69 \\
\hline Male & & 29 & & & 30 & & \\
\hline Female & & 21 & & & 20 & & \\
\hline Age (years) & $63 \cdot 6$ & $8 \cdot 8$ & 63.5 & $62 \cdot 7$ & $13 \cdot 2$ & $67 \cdot 0$ & 0.89 \\
\hline Body height $(\mathrm{cm})$ & 161 & 9 & 161 & 160 & 9 & 161 & 0.86 \\
\hline Body weight (kg) & 60 & 13 & 55 & 59 & 10 & 56 & 0.72 \\
\hline \multicolumn{8}{|l|}{ Pain caused by PHN } \\
\hline Pain durationt (months) & & & & $14 \cdot 8$ & $17 \cdot 4$ & 6 & \\
\hline Average NRS $(0-10) \ddagger$ & & & & $6 \cdot 1$ & $2 \cdot 1$ & 6 & \\
\hline
\end{tabular}

NRS, numeric rating pain scale.

* The $\chi^{2}$ test was used to test the difference in sex. Statistical differences in age, body height and body weight between the two groups were analysed using the Mann-Whitney $U$ test.

$\dagger$ Duration of pain since zoster skin rash onset.

$\ddagger$ The intensity of average daily pain on an eleven-point numeric rating pain scale in the previous day. 
Table 2. Profiles of the nine selected circulating nutrients measured in plasma/serum in healthy controls and postherpetic neuralgia (PHN) patients*

(Mean values, standard deviations and medians)

\begin{tabular}{|c|c|c|c|c|c|c|c|}
\hline & \multicolumn{3}{|c|}{ Controls ( $n 50)$} & \multicolumn{3}{|c|}{ PHN patients ( $n 50)$} & \multirow[b]{2}{*}{$P$} \\
\hline & Mean & SD & Median & Mean & SD & Median & \\
\hline Ionised $\mathrm{Ca}(\mathrm{mmol} / \mathrm{l})$ & $1 \cdot 10$ & 0.08 & 1.13 & 1.00 & 0.08 & 1.03 & $<0.001$ \\
\hline $\mathrm{Zn}(\mathrm{g} / \mathrm{l})$ & 0.97 & 0.11 & 0.96 & 0.84 & 0.11 & 0.86 & $<0.001$ \\
\hline Retinol $(\mu \mathrm{mol} / \mathrm{l})$ & 1.96 & 0.53 & 1.94 & $2 \cdot 15$ & 0.76 & 1.98 & 0.27 \\
\hline Folic acid (nmol/l) & 31.7 & $16 \cdot 1$ & 33.1 & $27 \cdot 8$ & $18 \cdot 4$ & 33.0 & 0.09 \\
\hline Vitamin $\mathrm{B}_{12}(\mathrm{pmol} / \mathrm{l})$ & 486 & 125 & 451 & 1031 & 103 & 670 & 0.003 \\
\hline Vitamin $\mathrm{B}_{12} \dagger(\mathrm{pmol} / \mathrm{l})$ & 486 & 125 & 451 & 354 & 118 & 418 & 0.002 \\
\hline Vitamin C $(\mu \mathrm{mol} / \mathrm{l})$ & $76 \cdot 2$ & $31 \cdot 2$ & 74.4 & $30 \cdot 0$ & $20 \cdot 8$ & $17 \cdot 6$ & $<0.001$ \\
\hline$\alpha$-Tocopherol $(\mu \mathrm{mol} / \mathrm{l})$ & $26 \cdot 1$ & 7.4 & 24.4 & $30 \cdot 0$ & $10 \cdot 2$ & $29 \cdot 0$ & 0.021 \\
\hline$\alpha$-Tocopherol¥ ( $\mu \mathrm{mol} / \mathrm{l})$ & $26 \cdot 1$ & $7 \cdot 4$ & 24.4 & $25 \cdot 1$ & 7.4 & 24.4 & 0.82 \\
\hline$\gamma$-Tocopherol $(\mu \mathrm{mol} / \mathrm{l})$ & 2.79 & 1.63 & 2.35 & 2.09 & 1.86 & 1.69 & 0.007 \\
\hline$\gamma$-Tocopherol $\neq(\mu \mathrm{mol} / \mathrm{l})$ & $2 \cdot 79$ & 1.63 & $2 \cdot 35$ & 3.02 & 2.09 & 2.41 & 0.75 \\
\hline Lycopene $(\mu \mathrm{mol} / \mathrm{l})$ & $0 \cdot 14$ & 0.09 & 0.11 & 0.11 & 0.08 & 0.09 & 0.22 \\
\hline
\end{tabular}

* The Mann-Whitney $U$ test was used to test the differences in concentrations of the nine selected circulating nutrients between healthy controls and PHN patients.

† Data in this row do not include the twenty-eight PHN patients receiving vitamin $\mathrm{B}_{12}$ supplements after outbreaks of herpes zoster ( $\mathrm{HZ}$ ).

$\ddagger$ Data in this row do not include the twenty-three PHN patients taking $\alpha$-tocopherol supplements after outbreaks of $\mathrm{HZ}$.

supplements were not significantly different from those in controls $(P=0.74)$. In contrast, geometric mean concentrations of $\alpha$-tocopherol in twenty-three PHN patients taking $\alpha$-tocopherol supplements were 51.3-fold, compared with those of $\gamma$-tocopherol. Moreover, $\alpha$ : $\gamma$-tocopherol ratios in twenty-three PHN patients taking $\alpha$-tocopherol supplements were higher than those in controls $(P<0 \cdot 001)$. Strikingly, the top three $\alpha: \gamma$-tocopherol ratios in those PHN patients taking $\alpha$-tocopherol supplements were greater than 100 (data not shown). These results confirm an interaction between plasma concentrations of $\alpha$-tocopherol and $\gamma$-tocopherol, as previous studies have demonstrated that $\alpha$-tocopherol supplements cause a reduction in $\gamma$-tocopherol concentration in the plasma ${ }^{(34)}$.

\section{Nutrient deficiencies in controls and postherpetic} neuralgia patients

In Table 4, two cut-off points for plasma nutrient deficiencies including a severe deficiency and a mild/marginal deficiency are used for ionised $\mathrm{Ca}^{(35,36)}, \mathrm{Zn}^{(29,30)}$, retinol ${ }^{(37,38)}$, $\alpha$-tocopherol ${ }^{(37)}$, vitamin $\mathrm{C}^{(39)}$, vitamin $\mathrm{B}_{12}^{(40)}$ and folic acid ${ }^{(41)}$. As of yet, $\gamma$-tocopherol and lycopene are not established nutrients, so their deficiency levels have not been established. The concentration ranges of $\boldsymbol{\gamma}$-tocopherol and lycopene in human plasma were $0.65-2.05 \mu \mathrm{g} / \mathrm{ml}^{(42)}$ and $0.07-1.79 \mathrm{~mol} / \mathrm{l}^{(32)}$ individually. Thus, less than $1.5 \mu \mathrm{mol} / \mathrm{l}(0.65 \mu \mathrm{g} / \mathrm{ml})$ for $\gamma$-tocopherol and less than $0.07 \mathrm{~mol} / 1(37.5 \mu \mathrm{g} / \mathrm{l})$ for lycopene were used as the cut-off points of a mild/marginal deficiency. According to the normal ranges of controls in our laboratory (Table 2), we used $<1.1 \mu \mathrm{mol} / 1 \quad(0.47 \mu \mathrm{g} / \mathrm{ml})$ for $\gamma$-tocopherol and $<0.05 \mu \mathrm{mol} / 1(26.8 \mu \mathrm{g} / \mathrm{l})$ for lycopene as the cut-off points of a severe deficiency. Percentages of PHN patients with subnormal plasma concentrations were ranked from highest to lowest (Table 4): Zn, 64\%; vitamin C, 52\%; $\gamma$-tocopherol, $44 \%$; ionised $\mathrm{Ca}, 36 \%$; lycopene, 30\%; folic acid, $12 \%$; $\alpha$-tocopherol, $10 \%$; vitamin $\mathrm{B}_{12}, 6 \%$; retinol, $4 \%$. However, including $\gamma$-tocopherol in the list of low concentration nutrients in PHN patients was unjustified, because $46 \%$ of our PHN patients took oral $\alpha$-tocopherol supplements ${ }^{(34)}$, which can decrease $\gamma$-tocopherol concentrations in the plasma since outbreaks of HZ.

The prevalence of either mild/marginal or severe deficiencies for any of the nine selected circulating nutrients in PHN patients (92\%) was much higher than that of controls (46\%, $P<0 \cdot 001)$. The average element $2 \cdot 0$ (SD $1 \cdot 1$; median 2 ) of either mild/marginal or severe deficiencies for any of the nine selected circulating nutrients in PHN patients was significantly higher than that 0.6 (SD 0.7 ; median 0 ) of the controls $(P<0 \cdot 001)$. Furthermore, the prevalence of either

Table 3. Profiles of $\alpha$-tocopherol, $\gamma$-tocopherol and the $\alpha$ : $\gamma$-tocopherol ratio in controls and postherpetic neuralgia (PHN) patients* (Mean values, standard deviations and medians)

\begin{tabular}{|c|c|c|c|c|c|c|c|c|c|c|c|}
\hline & \multicolumn{3}{|c|}{ Controls ( $n 50)$} & \multicolumn{3}{|c|}{ PHN, S(-) (n 27) } & \multirow[b]{2}{*}{$P \dagger$} & \multicolumn{3}{|c|}{$\mathrm{PHN}, \mathrm{S}(+)(n 23)$} & \multirow[b]{2}{*}{$P \neq$} \\
\hline & Mean & SD & Median & Mean & SD & Median & & Mean & SD & Median & \\
\hline$\alpha$-Tocopherol $(\mu \mathrm{mol} / \mathrm{l})$ & $26 \cdot 1$ & $7 \cdot 4$ & $24 \cdot 4$ & $25 \cdot 1$ & $7 \cdot 4$ & $24 \cdot 4$ & 0.82 & $35 \cdot 6$ & $10 \cdot 2$ & 33.0 & $<0.001$ \\
\hline$\gamma$-Tocopherol $(\mu \mathrm{mol} / \mathrm{l})$ & $2 \cdot 79$ & 1.63 & $2 \cdot 35$ & 3.02 & 2.09 & $2 \cdot 41$ & 0.75 & $1 \cdot 16$ & 0.70 & $1 \cdot 16$ & 0.004 \\
\hline$\alpha: \gamma$-Tocopherol & $10 \cdot 8$ & $5 \cdot 3$ & $9 \cdot 6$ & $9 \cdot 9$ & 3.8 & $10 \cdot 1$ & 0.74 & $51 \cdot 3$ & $48 \cdot 7$ & 31.5 & $<0.001$ \\
\hline
\end{tabular}

$\mathrm{S}(-)$, without $\alpha$-tocopherol supplements; $\mathrm{S}(+)$, with $\alpha$-tocopherol supplements.

* The Mann-Whitney $U$ test was used to test the differences in $\alpha$-tocopherol, $\gamma$-tocopherol and the $\alpha: \gamma$-tocopherol ratio between controls and PHN patients.

$\dagger$ Difference between controls and PHN patients without $\alpha$-tocopherol supplements.

$\ddagger$ Difference between controls and PHN patients with $\alpha$-tocopherol supplements. 
Table 4. Severe and mild nutrient deficiencies in healthy controls and postherpetic neuralgia (PHN) patients (Number of subjects and percentages)

\begin{tabular}{|c|c|c|c|c|c|c|}
\hline & & \multirow[b]{2}{*}{ Cut-off or range* } & \multicolumn{2}{|c|}{ Controls ( $n 50)$} & \multicolumn{2}{|c|}{ PHN patients $(n 50)$} \\
\hline & & & Subjects $(n)$ & $\%$ & Subjects $(n)$ & $\%$ \\
\hline \multirow[t]{2}{*}{ Ionised $\mathrm{Ca}$} & Cut-off & $<0.8 \mathrm{mmol} / \mathrm{l}(32 \mu \mathrm{g} / \mathrm{ml})$ & 0 & 0 & 1 & 2 \\
\hline & Range & $0.8-1.0 \mathrm{mmol} / \mathrm{l}$ & 3 & 6 & 17 & 34 \\
\hline \multirow[t]{2}{*}{$\mathrm{Zn}$} & Cut-off & $<0.7 \mathrm{~g} / \mathrm{l}(10.7 \mu \mathrm{mol} / \mathrm{l})$ & 1 & 2 & 7 & 14 \\
\hline & Range & $0.7-0.9 \mathrm{~g} / \mathrm{l}$ & 9 & 18 & 25 & 50 \\
\hline \multirow[t]{2}{*}{ Retinol } & Cut-off & $<0.7 \mu \mathrm{mol} / \mathrm{l}(200 \mu \mathrm{g} / \mathrm{l})$ & 0 & 0 & 0 & 0 \\
\hline & Range & $0.7-1.1 \mu \mathrm{mol} / \mathrm{l}$ & 0 & 0 & 2 & 4 \\
\hline \multirow[t]{2}{*}{ Folic acid } & Cut-off & $<6.8 \mathrm{nmol} / \mathrm{l}(3 \mathrm{ng} / \mathrm{ml})$ & 0 & 0 & 0 & 0 \\
\hline & Range & $6 \cdot 8-13.6 \mathrm{nmol} / \mathrm{l}$ & 0 & 0 & 6 & 12 \\
\hline \multirow[t]{2}{*}{ Vitamin $B_{12}$} & Cut-off & $<148 \mathrm{pmol} / \mathrm{l}(0.2 \mathrm{ng} / \mathrm{ml})$ & 0 & 0 & $1(1 / 22,0 / 28) \dagger$ & 2 \\
\hline & Range & $148-222 \mathrm{pmol} / \mathrm{l}$ & 1 & 2 & $2(2 / 22,0 / 28) \dagger$ & 4 \\
\hline \multirow[t]{2}{*}{ Vitamin C } & Cut-off & $<11.3 \mu \mathrm{mol} / \mathrm{l}(2 \mu \mathrm{g} / \mathrm{ml})$ & 0 & 0 & 0 & 0 \\
\hline & Range & $11.3-22.6 \mu \mathrm{mol} / \mathrm{l}$ & 0 & 0 & 26 & 52 \\
\hline \multirow[t]{2}{*}{$\alpha$-Tocopherol } & Cut-off & $<11.63 \mu \mathrm{mol} / \mathrm{l}(5 \mu \mathrm{g} / \mathrm{ml})$ & 0 & 0 & $0(0 / 27,0 / 23) \ddagger$ & 0 \\
\hline & Range & $11.63-16.28 \mu \mathrm{mol} / \mathrm{l}$ & 2 & 4 & $5(5 / 27,0 / 23) \ddagger$ & 10 \\
\hline \multirow[t]{2}{*}{$\gamma$-Tocopherol } & Cut-off & $<1.1 \mu \mathrm{mol} / /(0.47 \mu \mathrm{g} / \mathrm{ml})$ & 4 & 8 & $14(1 / 27,13 / 33) \ddagger$ & 28 \\
\hline & Range & $1.1-1.5 \mu \mathrm{mol} / \mathrm{l}$ & 5 & 10 & $8(3 / 27,5 / 23) \ddagger$ & 16 \\
\hline \multirow{2}{*}{ Lycopene } & Cut-off & $<0.05 \mu \mathrm{mol} / \mathrm{l}(26.8 \mu \mathrm{g} / \mathrm{l})$ & 10 & 20 & 13 & 26 \\
\hline & Range & $0.05-0.07 \mu \mathrm{mol} / \mathrm{l}$ & 4 & 8 & 2 & 4 \\
\hline
\end{tabular}

* The cut-off value is the cut-off point for severe deficiency. The range values are the range for mild-marginal deficiency.

$\dagger$ Of the fifty PHN patients, twenty-eight patients received vitamin $B_{12}$ supplements after outbreaks of herpes zoster (HZ) whereas the other twenty-two patients did not receive vitamin $\mathrm{B}_{12}$ supplements after outbreaks of $\mathrm{HZ}$.

$\ddagger$ Of the fifty PHN patients, twenty-three patients took $\alpha$-tocopherol supplements after outbreaks of $\mathrm{HZ}$ whereas the other twenty-seven patients did not take $\alpha$-tocopherol supplements after outbreaks of $\mathrm{HZ}$.

mild/marginal or severe deficiencies of any of the three suspected circulating nutrients (vitamin $\mathrm{C}$, ionised $\mathrm{Ca}$ or $\mathrm{Zn}$ ) was $90 \%$ in PHN patients and $22 \%$ in controls $(P<0 \cdot 001)$. The average element of either mild/marginal or severe deficiencies for any of the three suspected circulating nutrients in PHN patients was 1.6 (SD 0.8; median 2), compared with that 0.3 (SD 0.5; median 0 ) of controls $(P<0.001)$. Not surprisingly, a combination of deficiencies of any two of the three suspected circulating nutrients in the fifty PHN patients was the most predominant pattern with a proportion of $58 \%$ (twenty-nine out of fifty; data not shown).

Relative risks of postherpetic neuralgia associated with plasma concentrations of the seven nutrients and the $\alpha$ : $\gamma$-tocopherol ratio

Owing to the interaction between plasma concentrations of $\alpha$-tocopherol and $\gamma$-tocopherol, we used the $\alpha: \gamma$-tocopherol ratio $^{(34)}$ as a variable instead of plasma concentrations of $\alpha$-tocopherol and $\gamma$-tocopherol in a multivariate multiple logistic regression model. Consequently, the $\alpha: \gamma$-tocopherol ratio and plasma concentrations of the seven nutrients were dichotomised into binary variables by median based on both controls and PHN patients to identify the risk factors of PHN using a multivariate multiple logistic regression model by forward stepwise procedures.

Table 5 indicates that patients with lower concentrations of plasma vitamin $\mathrm{C}$, ionised $\mathrm{Ca}$ or serum $\mathrm{Zn}$ had significantly higher risks of PHN. There were no significant correlations between the risk of PHN and the concentrations of retinol, lycopene, vitamin $\mathrm{B}_{12}$, folic acid or the ratio of $\alpha: \gamma$-tocopherol. The value of the $C$-statistic is 0.93 (95\% CI $0.88,0.98$ ), indicating a good prediction model.

\section{Discussion}

To our knowledge, this is the first case-control study to investigate the plasma status of nutrients in PHN patients and to

Table 5. Postherpetic neuralgia (PHN) estimated using the forward selected logistic regression model ${ }^{\star}$ (Adjusted odds ratios and $95 \%$ confidence intervals)

\begin{tabular}{|c|c|c|c|c|}
\hline Nutrient binary cut-offs & Cases-controls & Adjusted OR & $95 \% \mathrm{Cl}$ & $P$ \\
\hline \multicolumn{5}{|c|}{ Vitamin C (normal range $26.1-84.6 \mu \mathrm{mol} / \mathrm{l})$} \\
\hline$>45.0 \mu \mathrm{mol} / \mathrm{l}(8.0 \mu \mathrm{g} / \mathrm{ml})$ & $8 / 42$ & 1.0 & & \\
\hline$\leq 45.0$ & $42 / 8$ & $20 \cdot 58$ & $5 \cdot 55,76 \cdot 26$ & $<0.001$ \\
\hline \multicolumn{5}{|c|}{ lonised $\mathrm{Ca}$ (normal range $1.14-1.30 \mathrm{mmol} / \mathrm{l})$} \\
\hline$>1.05 \mathrm{mmol} / \mathrm{l}(42 \mu \mathrm{g} / \mathrm{ml})$ & $16 / 43$ & $1 \cdot 0$ & & \\
\hline$\leq 1.05$ & $34 / 7$ & $12 \cdot 80$ & $3 \cdot 17,51 \cdot 68$ & $<0.001$ \\
\hline \multicolumn{5}{|l|}{$\mathrm{Zn}$ (normal range $0.9-1.3 \mathrm{~g} / \mathrm{l})$} \\
\hline$>0.91 \mathrm{~g} / \mathrm{l}(13.9 \mu \mathrm{mol} / \mathrm{l})$ & $13 / 36$ & 1.0 & & \\
\hline$\leq 0.91$ & $37 / 14$ & 5.42 & $1.51,19.50$ & 0.01 \\
\hline
\end{tabular}


analyse the association between nutrient status and the risk of PHN. Among the nine selected nutrients, we discovered that concentrations of vitamin $\mathrm{C}, \mathrm{Zn}$, ionised $\mathrm{Ca}$ and vitamin $\mathrm{B}_{12}$ in $\mathrm{PHN}$ patients were lower than those in the control group after excluding the patients who received vitamin $B_{12}$ and $\alpha$-tocopherol supplements after the outbreaks of HZ. Of the fifty PHN patients, forty-six (92\%) had either mild/ marginal or severe deficiencies in at least one of the nine circulating nutrients (Table 4). Lower concentrations of vitamin $\mathrm{C}(\leq 45.0 \mu \mathrm{mol} / \mathrm{l})$, ionised $\mathrm{Ca}(\leq 1.05 \mathrm{mmol} / \mathrm{l})$ and $\mathrm{Zn}(\leq 0.91 \mathrm{~g} / \mathrm{l})$ were found to increase independently the risk of PHN using binary variable (dichotomy) analyses using both PHN patients and controls in a multivariate logistic regression analysis.

Possible causes of nutrient deficiencies include inadequate intake of nutrients, increased requirements of nutrients, malabsorption, utilisation dysfunction or drug-nutrient interactions $^{(43)}$. The present study was a case-control crosssectional study that does not allow us to determine whether nutrient deficiencies in PHN patients are a cause or a result. Nevertheless, based on the following reasons, we speculate that the nutrient deficiencies in PHN patients may be a preexisting condition and then worsened by the disease process and taking inappropriate supplements such as excessive $\alpha$ tocopherol.

We found that $52 \%$ of the PHN patients had a marginal deficiency of plasma vitamin C. In contrast, the mean concentration of vitamin $C$ in our controls was $76 \cdot 2$ (SD 31.2) $\mu \mathrm{mol} / \mathrm{l}$. The Elderly Nutrition and Health Survey in Taiwan from 1999 to 2000 reported that the mean intake of vitamin $\mathrm{C}$ in healthy elderly Taiwanese is $148 \mathrm{mg} / \mathrm{d}$ derived from $24 \mathrm{~h}$ recalls ${ }^{(44)}$. Male subjects with a daily intake of $150 \mathrm{mg}$ ascorbic acid and female subjects with a daily intake of $80 \mathrm{mg}$ ascorbic acid reach a maximum plasma steady-state level $(56.78 \mu \mathrm{mol} / 1$ or $10 \mathrm{mg} / \mathrm{l})$ of ascorbic $\operatorname{acid}^{(45)}$. Not surprisingly, the mean plasma concentration of vitamin $\mathrm{C}$ in our controls approached the high level of the normal range ${ }^{(27)}$. Vitamin C is an essential nutrient for humans, because humans lack the ability to synthesise vitamin $\mathrm{C}^{(46)}$. A community-based casecontrol study using a FFQ attributes people with a higher risk for $\mathrm{HZ}$ to a chronic low intake of vitamin $\mathrm{C}^{(7)}$. The present results accorded well with the previous study in a temporal sequence from $\mathrm{HZ}$ to $\mathrm{PHN}$ to explain nutrient deficiencies in PHN patients as a pre-existing condition. A second reason is that an unexpectedly high prevalence of mild $(0 \cdot 8-1.0 \mathrm{mmol} / \mathrm{l})$ and severe hypocalcaemia $(<0.8 \mathrm{mmol} / \mathrm{l})$, i.e. $36 \%$ of the PHN (eighteen out of fifty) patients, was observed. The mean concentration of $1 \cdot 10$ (SD 0.08$) \mathrm{mmol} / 1$ of ionized $\mathrm{Ca}$ in our controls was lower than the normal range $(1 \cdot 14-1.30 \mathrm{mmol} / \mathrm{l})^{(28)}$, because the Elderly Nutrition and Health Survey in Taiwan from 1999 to 2000 showed that the mean total $\mathrm{Ca}$ intake for all elderly participants reaches only $62-64 \%$ of the dietary reference intakes ${ }^{(44)}$. Of the eighteen patients with an unexpectedly high prevalence of mild or severe hypocalcaemia, thirteen had been hospitalised due to malignant diseases, haemorrhagic peptic ulcer diseases, severe infective diseases and hyperosmolar hyperglycaemic states. These comorbid conditions, classed as either chronic or frequently recurrent, were commonly associated with inadequate intake of nutrients, increasing requirements of nutrients, malabsorption or utilisation dysfunction. Hence, we speculated that hypocalcaemia in those $\mathrm{PHN}$ patients was pre-existing. A third reason is that $64 \%$ of fifty PHN patients in the present study exhibited either a severe $\mathrm{Zn}$ deficiency (seven patients) or a mild Zn deficiency (twentyfive patients) ${ }^{(29)}$. Of these seven patients, five had hypocalcaemia plus a history of hospitalisation. By coincidence, three of these seven patients had a mild deficiency of vitamin C. $\mathrm{Zn}$ is an acute-phase reactant, and prolonged low serum $\mathrm{Zn}$ level is common after acute viral infection is resolved ${ }^{(9)}$. In addition, serum $\mathrm{Zn}$ levels usually decrease as chronic viral disease progresses $^{(9)}$. Thus, lower concentrations of $\mathrm{Zn}$ in PHN patients may be a pre-existing condition and then worsened by the disease process. A fourth reason is that decreasing food intake in the process of PHN may partly deteriorate the nutrient status in PHN patients. Psychological distress and pain are usually developed in the aftermath of $\mathrm{HZ}$ and $\mathrm{PHN}^{(2)}$. As a result, decreasing food intake has been found to be a common sequela of psychological distress and pain ${ }^{(47)}$ and to worsen the nutrient status in PHN patients. These observations support our contention that nutrient deficiencies in PHN patients are a pre-existing condition which are then worsened by the disease process.

We also demonstrated that patients with lower concentrations of either plasma vitamin $\mathrm{C}(\leq 45.0 \mu \mathrm{mol} / \mathrm{l})$, ionised $\mathrm{Ca}(\leq 1.05 \mathrm{mmol} / \mathrm{l})$ or serum $\mathrm{Zn}(\leq 0.91 \mathrm{~g} / \mathrm{l})$ had significantly higher risks of PHN. Nutrients are known to play important roles in both the modulation of neuropathic pain and host resistance to viruses. In evidence-based guidelines, prophylactic vitamin $\mathrm{C}$ is recommended for the prevention of a peripheral neuropathic pain syndrome - complex regional pain syndrome type $\mathrm{I}^{(14-16)}$. Systemic injection of $\mathrm{Zn}$ alleviates neuropathic pain in rats ${ }^{(23)}$. Furthermore, ascorbate ${ }^{(24)}$ and $\mathrm{Zn}^{(25)}$ are $\mathrm{Ca}(\mathrm{v}) 3.2 \mathrm{~T}$-channel blockers. $\mathrm{Ca}(\mathrm{v}) 3.2 \mathrm{~T}$-channels are the predominant $\mathrm{T}$-channel isoform in dorsal root ganglion neurons ${ }^{(48)}$ which contribute to peripheral sensitisation. Consequently, a T-type Ca channel blocker decreases neuropathic pain in rats ${ }^{(49)}$. A decrease in Ca concentrations alters excitability of neurons to enhance pain transmission in rats ${ }^{(17)}$. In view of cellular immunity, a decline in cellular immunity to VZV is crucial in the aetiology of $\mathrm{HZ}$ and $\mathrm{PHN}^{(1)}$. Vitamin $\mathrm{C}$ possesses a reversible concentration-dependent antiviral activity, and the continuous presence of ascorbic acid is needed to keep viruses suppressed ${ }^{(11)}$. Similarly, virus replication inhibited by $\mathrm{Zn}$ is concentration dependent and reversible in cell cultures ${ }^{(50)}$. In the past decade, immune cell activation by intracellular Ca signalling has been well known ${ }^{(51)}$. Hypocalcaemia is associated with decreased intracellular Ca stored in peripheral mononuclear cells, which leads to host immune suppression ${ }^{(13)}$. On the contrary, the effect of glycoprotein $\mathrm{E}$ of VZV on the formation of cell-cell contacts was $\mathrm{Ca}^{2+}$ independent ${ }^{(52)}$. Under low Ca conditions, VZV glycoprotein $\mathrm{E}$ still functions well in promoting cell-cell contact which is a viral highway for the cell-cell spread of $\mathrm{VZV}^{(52)}$. Thus, low $\mathrm{Ca}$ conditions can tip the balance between host immunity and viral pathogenicity adversely. Accordingly, 
PHN patients with lower plasma vitamin C, ionised Ca or serum $\mathrm{Zn}$ may have inadequate antiviral immunity. Therefore, ongoing viral replications in the dorsal root ganglion may render chronic VZV ganglionitis ${ }^{(1)}$ susceptible to prolonged PHN by central neuroinflammation ${ }^{(53)}$.

Despite the careful design of the present study, some limitations do exist. First, although we had surveyed a total of nine nutrients in the plasma, there may be additional nutrient deficiencies which are associated with increased risks of PHN. In this context, it would be difficult, if not impossible, to survey all of the neuropathic pain/immunity-related nutrient factors by any study. Second, we included PHN patients based on clinical diagnosis, which is not a precise characterisation of the study population. It is possible that the distinct subsets of patients, e.g. patient heterogeneity, or patient selection would affect the data analysis. Third, the present study did not include a FFQ to measure dietary intakes. Thereby, we cannot determine the association between food intakes and plasma levels of the selected circulating nutrients in our PHN patients. A fourth limitation is that the patient numbers of the present study were small; thus large-scale investigations are required to confirm the present findings in the future. Additionally, the patient numbers of the study were too small to analyse the synergic effect between nutrients in logistic regression analyses.

In conclusion, the present study shows that a majority (92\%) of Taiwanese PHN patients have either mild/marginal or severe deficiencies in at least one of the nine selected circulating nutrients. Furthermore, the prevalence of either mild/marginal or severe deficiencies for any of the three suspected circulating nutrients (vitamin $\mathrm{C}$, ionised $\mathrm{Ca}$ or $\mathrm{Zn}$ ) in PHN patients was $90 \%$. Lower concentrations of vitamin C $(\leq 45.0 \mu \mathrm{mol} / \mathrm{l})$, ionised $\mathrm{Ca} \quad(\leq 1.05 \mathrm{mmol} / \mathrm{l})$ and $\mathrm{Zn}$ $(\leq 0.91 \mathrm{~g} / \mathrm{l})$ were found to increase independently the risk of PHN using binary variable (dichotomy) analyses with both PHN patients and controls in a multivariate logistic regression analysis. The present results demonstrate that lower concentrations of circulating nutrients, namely vitamin $\mathrm{C}$, ionised $\mathrm{Ca}$ and $\mathrm{Zn}$, are a risk factor in Taiwanese patients with PHN. However, there is a need to clarify whether there are significant geographical variations; thus investigations into other populations are required to confirm these findings.

\section{Acknowledgements}

The present study was supported by a grant (CMFHR9850) provided by the Chi Mei Medical Center, Tainan, Taiwan. There is no conflict of interest for any of the authors. J.-Y. C. was involved in the study concept and design; J.-Y. C., C.-C. C., Y.-S. L. and E. C. S. were responsible for the acquisition of the data; J.-P. S. conducted the statistical analyses; M.-L. H. participated in the study supervision. We appreciate the helpful remarks from Professor Wei-Zen Sun, Department of Anesthesiology, National Taiwan University Hospital, Taipei, Taiwan. We thank the nurses (Wen Ju, Wu and Yu Li, Cheng) for their help in the study.

\section{References}

1. Arvin AM (1996) Varicella-zoster virus. Clin Microbiol Rev 9 , 361-381.

2. Dworkin RH, Gnann JW Jr, Oaklander AL, et al. (2008) Diagnosis and assessment of pain associated with herpes zoster and postherpetic neuralgia. J Pain 9, S37-S44.

3. Jung BF, Johnson RW, Griffin DR, et al. (2004) Risk factors for postherpetic neuralgia in patients with herpes zoster. Neurology 62, 1545-1551.

4. Mueller NH, Gilden DH, Cohrs RJ, et al. (2008) Varicella zoster virus infection: clinical features, molecular pathogenesis of disease, and latency. Neurol Clin 26, 675-697, vii.

5. Chandra RK (2002) Nutrition and the immune system from birth to old age. Eur J Clin Nutr 56, Suppl. 3, S73-S76.

6. Maggini S, Wintergerst ES, Beveridge S, et al. (2007) Selected vitamins and trace elements support immune function by strengthening epithelial barriers and cellular and humoral immune responses. Br J Nutr 98, Suppl. 1, S29-S35.

7. Thomas SL, Wheeler JG \& Hall AJ (2006) Micronutrient intake and the risk of herpes zoster: a case-control study. Int J Epidemiol 35, 307-314.

8. Chen JY, Chang CY, Feng PH, et al. (2009) Plasma vitamin C is lower in postherpetic neuralgia patients and administration of vitamin $\mathrm{C}$ reduces spontaneous pain but not brush-evoked pain. Clin J Pain 25, 562-569.

9. Patrick L (2000) Nutrients and HIV: part two - vitamins A and E, zinc, B-vitamins, and magnesium. Altern Med Rev $\mathbf{5}$, $39-51$.

10. Jariwalla RJ \& Harakeh S (1996) Antiviral and immunomodulatory activities of ascorbic acid. Subcell Biochem 25 , 213-231.

11. Furuya A, Uozaki M, Yamasaki H, et al. (2008) Antiviral effects of ascorbic and dehydroascorbic acids in vitro. Int $J$ Mol Med 22, 541-545.

12. Chew BP \& Park JS (2004) Carotenoid action on the immune response. J Nutr 134, 257S-261S.

13. Kimura K, Reinhardt TA \& Goff JP (2006) Parturition and hypocalcemia blunts calcium signals in immune cells of dairy cattle. J Dairy Sci 89, 2588-2595.

14. Zollinger PE, Tuinebreijer WE, Kreis RW, et al. (1999) Effect of vitamin $\mathrm{C}$ on frequency of reflex sympathetic dystrophy in wrist fractures: a randomised trial. Lancet 354, 2025-2028.

15. Zollinger PE, Tuinebreijer WE, Breederveld RS, et al. (2007) Can vitamin $\mathrm{C}$ prevent complex regional pain syndrome in patients with wrist fractures? A randomized, controlled, multicenter dose-response study. J Bone Joint Surg Am 89, 1424-1431.

16. Perez RS, Zollinger PE, Dijkstra PU, et al. (2010) Evidence based guidelines for complex regional pain syndrome type 1. BMC Neurol 10, 20.

17. Wang T, Wang J, Cottrell JE, et al. (2004) Small physiologic changes in calcium and magnesium alter excitability and burst firing of CA1 pyramidal cells in rat hippocampal slices. J Neurosurg Anesthesiol 16, 201-209.

18. Martinez Figueroa A, Johnson RH, Lambie DG, et al. (1980) The role of folate deficiency in the development of peripheral neuropathy caused by anticonvulsants. I Neurol Sci 48, 315-323.

19. Arrieta O, Garcia-Navarrete R, Zuniga S, et al. (2005) Retinoic acid increases tissue and plasma contents of nerve growth factor and prevents neuropathy in diabetic mice. Eur J Clin Invest 35, 201-207.

20. Wang ZB, Gan Q, Rupert RL, et al. (2005) Thiamine, pyridoxine, cyanocobalamin and their combination inhibit thermal, 
but not mechanical hyperalgesia in rats with primary sensory neuron injury. Pain 114, 266-277.

21. Kim HK, Kim JH, Gao X, et al. (2006) Analgesic effect of vitamin $\mathrm{E}$ is mediated by reducing central sensitization in neuropathic pain. Pain 122, 53-62.

22. Kuhad A, Sharma S \& Chopra K (2008) Lycopene attenuates thermal hyperalgesia in a diabetic mouse model of neuropathic pain. Eur J Pain 12, 624-632.

23. Liu T, Walker JS \& Tracey DJ (1999) Zinc alleviates thermal hyperalgesia due to partial nerve injury. Neuroreport $\mathbf{1 0}$, 645-649.

24. Nelson MT, Joksovic PM, Su P, et al. (2007) Molecular mechanisms of subtype-specific inhibition of neuronal T-type calcium channels by ascorbate. J Neurosci 27, 12577-12583.

25. Traboulsie A, Chemin J, Chevalier M, et al. (2007) Subunitspecific modulation of T-type calcium channels by zinc. J Physiol 578, 159-171.

26. Chang CY, Chen JY, Ke D, et al. (2005) Plasma levels of lipophilic antioxidant vitamins in acute ischemic stroke patients: correlation to inflammation markers and neurological deficits. Nutrition 21, 987-993.

27. Lee W, Roberts SM \& Labbe RF (1997) Ascorbic acid determination with an automated enzymatic procedure. Clin Chem 43, 154-157.

28. Drop LJ, Tochka LN \& Misiano DR (1982) Comparative evaluation of two calcium ion-selective electrode systems, and their utility for monitoring steady-state changes in $\left[\mathrm{Ca}^{2+}\right]$. Clin Chem 28, 129-133.

29. Belbraouet S, Biaudet H, Tebi A, et al. (2007) Serum zinc and copper status in hospitalized vs. healthy elderly subjects. J Am Coll Nutr 26, 650-654.

30. Song YM \& Chen MD (2005) Relative reduced plasma zinc concentration in middle-aged but not elderly adults in Taiwan. Biol Trace Elem Res 103, 97-102.

31. Chen KJ, Pan WH, Yang FL, et al. (2005) Association of B vitamins status and homocysteine levels in elderly Taiwanese. Asia Pac J Clin Nutr 14, 250-255.

32. Mayne ST, Cartmel B, Silva F, et al. (1999) Plasma lycopene concentrations in humans are determined by lycopene intake, plasma cholesterol concentrations and selected demographic factors. $J$ Nutr 129, 849-854.

33. Tzeng MS, Yang FL, Wang GS, et al. (2004) Determination of major carotenoids in human serum by liquid chromatography. J Food Drug Anal 12, 79-83.

34. Handelman GJ, Machlin LJ, Fitch K, et al. (1985) Oral alpha-tocopherol supplements decrease plasma gammatocopherol levels in humans. J Nutr 115, 807-813.

35. Zaloga GP (1992) Hypocalcemia in critically ill patients. Crit Care Med 20, 251-262.

36. Bentrem DJ, Rademaker A \& Angelos P (2001) Evaluation of serum calcium levels in predicting hypoparathyroidism after total/near-total thyroidectomy or parathyroidectomy. $\mathrm{Am}$ Surg 67, 249-251, discussion 51-52.
37. Cheng WY, Fu ML, Wen LJ, et al. (2005) Plasma retinol and $\alpha$-tocopherol status of the Taiwanese elderly population. Asia Pac J Clin Nutr 14, 256-262.

38. High KP, Legault C, Sinclair JA, et al. (2002) Low plasma concentrations of retinol and alpha-tocopherol in hematopoietic stem cell transplant recipients: the effect of mucositis and the risk of infection. Am J Clin Nutr 76, 1358-1366.

39. Jacob RA, Otradovec CL, Russell RM, et al. (1988) Vitamin C status and nutrient interactions in a healthy elderly population. Am J Clin Nutr 48, 1436-1442.

40. Allen LH (2009) How common is vitamin B-12 deficiency? Am J Clin Nutr 89, 693S-696S.

41. Chen KJ, Pan WH, Shaw NS, et al. (2005) Association between dietary folate-rich food intake and folate status of elderly Taiwanese. Asia Pac J Clin Nutr 14, 244-249.

42. Behrens WA \& Madere R (1986) Alpha- and gamma tocopherol concentrations in human serum. J Am Coll Nutr 5 , 91-96.

43. Stambullian M, Feliu S \& Slobodianik NH (2007) Nutritional status in patients with HIV infection and AIDS. Br J Nutr 98, Suppl. 1, S140-S143.

44. Wu SJ, Chang YH, Wei IL, et al. (2005) Intake levels and major food sources of energy and nutrients in the Taiwanese elderly. Asia Pac J Clin Nutr 14, 211-220.

45. VanderJagt DJ, Garry PJ \& Bhagavan HN (1987) Ascorbic acid intake and plasma levels in healthy elderly people. Am J Clin Nutr 46, 290-294.

46. Jacob RA \& Sotoudeh G (2002) Vitamin C function and status in chronic disease. Nutr Clin Care 5, 66-74.

47. Marin Caro MM, Laviano A \& Pichard C (2007) Nutritional intervention and quality of life in adult oncology patients. Clin Nutr 26, 289-301.

48. Joksovic PM, Nelson MT, Jevtovic-Todorovic V, et al. (2006) CaV3.2 is the major molecular substrate for redox regulation of T-type $\mathrm{Ca}^{2+}$ channels in the rat and mouse thalamus. J Physiol 574, 415-430.

49. Todorovic SM, Meyenburg A \& Jevtovic-Todorovic V (2004) Redox modulation of peripheral T-type $\mathrm{Ca}^{2+}$ channels in vivo: alteration of nerve injury-induced thermal hyperalgesia. Pain 109, 328-339.

50. Shishkov S, Varadinova T, Bontchev P, et al. (1996) Complexes of zinc with picolinic and aspartic acids inactivate free varicella-zoster virions. Met Based Drugs 3, 11-14.

51. Grinstein S \& Klip A (1989) Calcium homeostasis and the activation of calcium channels in cells of the immune system. Bull N Y Acad Med 65, 69-79.

52. Mo C, Schneeberger EE \& Arvin AM (2000) Glycoprotein E of varicella-zoster virus enhances cell-cell contact in polarized epithelial cells. J Virol 74, 11377-11387.

53. Sweitzer SM, Hickey WF, Rutkowski MD, et al. (2002) Focal peripheral nerve injury induces leukocyte trafficking into the central nervous system: potential relationship to neuropathic pain. Pain 100, 163-170. 